\title{
Universalismo y pluralismo en la ética del discurso '
}

\author{
CRISTINA LAFONT \\ Northwestem University, Evanston
}

En este artículo se intenta mostrar cómo es posible defender un punto de vista universalista y cognitivista en cucstiones morales sin tener que negar el pluralismo ético que caracteriza a las sociedades modernas. Para ello se analiza una dificultad que ha sido planteada recientemente a la ética del discurso de Habermas en relación con la posibilidad de compaginar ambas cosas. Si defender un universalismo moral implica defender lo que Habermas denomina ula premisa de una respucsta corrccta» en relación con las cuestiones morales, tal universalismo tiene que suponer, pues, que sólo puede haber una interpretación correcta de dichas cuestiones; si csto es así, el universalismo moral, en realidad, excluye el pluralismo como alternativa racional al acuerdo en cuestiones prácticas. Dicha dificultad puede evitarse, sin cmbargo, si se muestra que «la premisa de una respucsta correcta» no implica, en realidad, «la premisa de una única interpretación correcta».

Como es sabido, el núcleo universalista de la ética del discurso se apoya en la posibilidad de defender el status cognitivo de las cuestiones morales. Desde el principio, Habermas ha mantenido esta posibilidad poniendo de relieve la analogía entre las cuestiones sobre corrección moral y las cuestiones sobre verdad. Sin duda, el alcance de esta analogía es polémico. Habermas mismo ha insistido repetidamente en lo impropio de postular un paralelismo demasiado estrecho (o incluso una asimilación) entre estos dos tipos diferentes de cuestiones. Analizando sus propias explicaciones no queda siempre claro, sin embargo, hasta qué punto exactamente cstos dos tipos de cuestiones se asemejan $-y$, evidentemente, precisar esto sería una tarea extremadamente difícilSin embargo, recientemente, a raíz de las críticas a Habermas de Thomas McCarthy ${ }^{2}$, se ha hecho patente que al menos algunos de los rasgos comuncs que subyacen a la lógica de las cuestiones morales y a la lógica de las cuestiones sobre verdad tendrían que ser especificados por Habermas para que el núcleo universalista de la ética del discurso pueda mantenerse. En su respuesta ${ }^{3}$ a McCarthy, Habermas ha unificado estos rasgos centrales bajo el rótulo de

\footnotetext{
'Traducción de José Medina.

"Vease T. McCarthy, "On the Relation of Morality and Politics", en Ideals and Ilusions, Cambridge, Mass., 1991. Más recientemente, «Legitimacy and Diversity: Dialectical Reflections on Analytical Distinctions», Cardozo Law Review, 17/14-5 (1996), pp. 1083-1127.

* Véase J. Habermas, «Reply» (R), Cardozo Law Review 17/4-5 (1996), pp. 1477-1559.
} 
«la prcmisa de "una única respuesta correcta"». Una defensa del status cognitivo de las cuestiones morales lleva consigo, necesariamente, mostrar que las cuestiones morales (claramente articuladas) sólo pueden tener «una única respuesta correcta» - tal como suponemos que es el caso respecto a las cuestiones sobre verdad-. Que en relación con ciertas cuestiones hay algo que saber significa que hay un hecho determinante de sus respuestas, que lo que puede saberse es de un modo u otro $-\mathrm{y}$ que, por tanto, no puede ser cl caso que una respuesta y su opucsta sean ambas correctas-.

Sin embargo, contra esta consecuencia -en mi opinión inevitableMcCarthy ha argumentado que la premisa de «una única respuesta correcta» entraña, como «idea regulativa» del discurso moral, que sólo puede haber una única interpretación correcta de las cuestiones morales. Por ello, dicha premisa implica la exclusión de ciertos tipos de pluralismo y desacuerdo como alternativas perfectamente racionales al acuerdo racional sobre cuestiones prácticas.

En lo que sigue trataré de cuestionar esta implicación mostrando que sólo se sigue del modo peculiar en que Habermas ha intentado hasta ahora defender la "premisa de "una única respuesta correcta"». En mi opinión, es perfectamente posible especificar el contenido de dicha premisa basándose en la concepción habermasiana de la racionalidad comunicativa de tal modo que las indeseadas consecuencias señaladas por McCarthy puedan evitarse sin que, por ello, sea necesario renunciar al sentido universalista de las cuestiones morales. Tal especificación no es, pues, sino un intento de determinar hasta qué punto el pluralismo tiene cabida en una perspectiva universalista sobre cuestiones morales.

Mi argumento se estructura en tres pasos. Primero voy a intentar especificar las presuposiciones comunes implícitas en el uso de términos normativos como «verdad» y «corrección» moral. Mostrar sus semejanzas estructurales ayudará a justificar la validez de «la premisa de "una única respuesta correcta" ${ }^{4}$ defendida por Habermas (I). En segundo lugar, me voy a referir a la defensa que Putnam ofrece de un pluralismo de interpretaciones en el ámbito de las cuestiones teóricas acerca de la verdad. Dicha discusión permite iluminar, en mi opinión, en qué sentido el pluralismo en cuestiones prácticas relativas a la corrección moral puede aceptarse igualmente sin menoscabar, por ello, su dimensión universal (II). Para defender este punto será necesario distinguir dos sentidos diferentes en los que puede entenderse la mencionada premisa (III). Una vez que estos dos sentidos son diferenciados, la aparente incompatibilidad entre universalismo y pluralismo desaparece.

${ }^{+}$En lo que sigue voy a intentar mostrar que las semejanzas estructurales entre cuestiones sobre la verdad y cuestiones sobre la validez moral se deben no a una semejanza de contenido sino a la inevitable conexión entre la "premisa de "una única respuesta correcta"” y cualquier pretensión de saber. Por tanto mi análisis se centra en esta conexión y no presta atención a las innegables diferencias de contenido. 
El tratamiento cognitivista de las cuestiones morales ofrecido por Habermas descansa en una reconstrucción pragmático-formal de la racionalidad comunicativa implícita en las prácticas comunicativas cotidianas. Más precisamente, se basa en las semejanzas estructurales que estas prácticas presentan cuando se plantean en ellas cuestiones relativas a la verdad de enunciados y a la corrección moral de normas de acción. Cuando hacemos afirmaciones sobre estos tipos de cuestiones, pretendemos que nuestras afirmaciones están justificadas. Esto sólo tiene sentido si presuponemos que tales cuestiones pueden decidirse de un modo racional, es decir, que dichas cuestiones ticnen una respuesta correcta que puede saberse. Por consiguiente, una posición cognitivista tiene que ofrecer una elucidación de la relación intcrna entre saber y justificación (o aceptabilidad racional).

El análisis pragmático-formal que Habermas ofrece de las presuposiciones indispensables inherentes a nuestras prácticas comunicativas pretende mostrar que hay un saber implicado no sólo cuando afirmamos la verdad de un enunciado, sino también cuando defendemos la corrección moral de una norma. Habermas defiende esta posición mostrando que tanto "verdad" como «corrección» moral son pretensiones de validez universales en la medida en que ambas pueden ser (y generalmente son) desempeñadas en un discurso teórico o práctico (es decir, esa peculiar forma de comunicación en la que las pretensiones de validez que se han vuelto problemáticas son examinadas para su justificación).

La caracterización pragmático-formal del discurso constituye, pues, a su vez, una interpretación discursiva de la noción de justificación o aceptabilidad racional. Este análisis muestra que la aceptabilidad racional de nuestro saber se hace tanto mas dependiente de la racionalidad de nuestros procedimientos de argumentación cuanto menos puede depender de contenido sustantivo alguno que pueda ser excluido a priori de ser problematizado. En este sentido, no hay una diferencia esencial entre el discurso teórico y el práctico con respecto a los rasgos formales de los procedimientos de argumentación racionalmente aceptables. La diferencia cntre ellos reside, pues, en el contenido, en los diferentes sentidos de las nociones de «verdad» y «corrección» moral: el saber implicado en nuestras afirmaciones de enunciados verdaderos depende de la existencia de ciertos estados de cosas en el mundo objetivo, mientras que el saber implicado en nuestra defensa de normas moralmente válidas depende de la existencia de intereses universalizables compartidos por todos los individuos en el mundo social. En Erläuterungen zur Diskursethik ${ }^{5}$ Habermas explica:

«Del mismo modo en que pucde explicarse el modo asertórico apelando a la existencia del estado de cosas afirmado, el modo deontológico puede explicarse apelando

J. Habermas, Erläutenungen zur Diskursethik (EDE), Francfort, 1991. 
a que las acciones exigidas están en el interés común de todos los posibles afectados» (EDE, p. 130).

El paralclismo entre estos dos tipos de cuestiones no depende, por tanto, de una asimilación entre cl modo asertórico y el modo deontológico de nuestros actos de habla. Depende más bien de la posibilidad de buscar la respuesta correcta a estas cuestiones en virtud de nuestra comprensión de las condiciones necesarias y suficientes para la satisfacción de ambas pretensiones de validez. Así como sabemos la condición necesaria y suficiente para la «verdad», que puede expresarse mediante la así llamada «Convención $T »:$ « " $p$ " es verdadero si y sólo si p», también sabemos la condición necesaria y suficiente para la «corrección» moral, que puede expresarse mediante un «principio moral»: una norma $\mathrm{N}$ es moralmente válida si y sólo si está igualmente en el interés de todos ${ }^{6}$.

Comprender el significado de estas pretensiones de validez es lo que permite a los participantes en un discurso teórico o práctico saber qué es lo que buscan en dicho discurso - lo que «racionalmente aceptable» significa, en cada caso, desde el punto de vista del contenido-. Pero si nos remitimos a las explicaciones de la teoria del discurso sobre el significado de las pretensiones de validez «verdad" y "corrección" moral, encontramos que ambas son supeditadas, a su vez, a un tipo de condición muy diferente de las mencionadas antes. Pues ambas son redefinidas en términos de la noción de «aceptabilidad racional en condiciones ideales»:

a) La pretensión de validez «verdad» se redefine en el artículo «Wahrheitstheorien» ${ }^{7}$ del modo siguiente: "La condición de la verdad de los enunciados es el acuerdo potencial de todos los otros (...). La verdad de una proposición significa la promesa de alcanzar un consenso racional sobre lo dicho» (WT, p. 137)

b) La pretensión de validez «corrección» ${ }^{8}$ moral se redefine en Faktizität

"El parajelismo al que nos referimos no radica, pucs, en semejanza de contenido alguna entre "Convención $T$ » $y$ dicho eprincipio morals, sino en que ambos agotan el sentido normativo de dichas pretensiones de validez, es decir, por medio de ellos es posible expresar las condiciones. necesarias y suficientes de las mismas. Esto es precisamente lo que permite considerar que ambas cuestiones son cognitivas -o, dicho de otro modo, esto es algo de to que no disponemos en relación con otros tipos de cuestiones posibles (como cuestiones de gusto, por ejemplo) y a lo que se debe que, por ello mismo, dichas cuestiones no puedan considerarse cuestiones cogritivas o dixcursivamente resolubles (es decir, ligadas a pretensiones de validez universales).

"J. Habermas, «Wahrheitstheorien» (WT), Vorsudien und Ergänzungen zur Theorie des kommunikativen Handelis, Francfort, 1984, pp. 127-186.

* Felmon John Davis ha apuntado ya la ambiguedad entre las dos definiciones de la «cortección* moral en su articulo eDiscourse Ethics and Ethical Realism: A Realist Realignment of Discourse Ethics», European Journal of Philosophy, 2 (1994), pp. 125-142. Aunque coincido plenamente con su análisis de las presuposiciones realistas implicitas en la ética del discurso, extraigo conclusiones muy diferentes acerca de la relación interna entre éstas y el discurso. 
und Geltung ${ }^{9}$ explicando ${ }^{10}$ el principio moral mencionado antes por medio del principio del discurso: «Son válidas aquellas normas de acción en las que podrían ponerse de acuerdo todos los posibles afectados en tanto que participantes en un discurso racional» ( $F G$, p. 138).

El sorprendente paralelismo entre estas definiciones parece ser la evidencia que da apoyo a la defensa de la semejanza estructural entre las cuestiones sobre verdad y sobre corrección moral por parte de Habermas. Pero, al mismo tiempo, es precisamente este paralelismo lo que hace que ambas redefiniciones resulten contraintuitivas en tanto que explicaciones del significado de "verdad" $y$ «corrección» moral. Si no se nos hubiese dicho antes que el acuerdo, en el primer caso, ha de ser un acuerdo sobre la existencia de estados de cosas en el mundo objetivo y, en el segundo caso, sobre la universalizabilidad de los intereses salvaguardados por la norma en cuestión, no habriamos sabido nunca, por medio de tales definiciones, cómo pueden discernir los participantes en los discursos respectivos qué es lo que han de buscar en estos diferentes casos.

La plausibilidad de estas definiciones como explicaciones de qué puede considerarse como un procedimiento de decisión racionalmente aceptable para cuestiones de verdad y corrección moral (en sociedades post-tradicionales) se pierde si, al mismo tiempo, tienen que ser entendidas como explicaciones de to que «verdad» $y$ «corrección» moral significan. Pero, si esto es correcto, las semejanzas estructurales entre los dos tipos de cuestiones no pueden derivarse, pues, de la asimilación de «verdad» y «corrección» moral a «aceptabilidad racional en condiciones ideales", como Habermas parece suponer ". Al contrario, tales semcjanzas mucstran sólo la relación intema cntre cstas dos pretensiones de validez y la pretensión de aceptabilidad racional. Una defensa del tratamiento cognitivista de ambos tipos de cuestiones consiste, precisamente, en un examen de dicha relación interna.

Como ya han observado muchos críticos, los participantes en un discurso tcórico o práctico necesitan cicrtamente saber cómo encontrar una respuesta acertada que pudiera ser aceptada como correcta por todos. Pero cuando

"J. Habermas, Faktizität und Geltung (FG), Francfort, 1992.

19. En Faktizität und Geltung (op. cit, pp. 135 y ss., esp, 140), Habermas reconoce la no identidad (cvidente) entre el principio moral y el principio del discurso, pero no parece reconocer, sin embargo, las consecuencias de la misma. Si el principio moral tiene un contenido obviamente diferente del contenido del principio del discurso, entonces este último no puede explicar al primero o, en otras palabras, la aceptabilidad racional no puede ser una condición para la validez de las normas morales sino más bien - como él mismo aclara - para ala posibilidad de una decisión racional de cuestiones prácticas» (p. 142); precisamente este carácter procedimental del principio del discurso to hace logicamente dependiente del contenido del principio moral (y, en el caso de los discursos teóricos, del contenido de la noción de verdad).

"Como voy a intentar mostrar en lo que sigue, no es que la noción de «aceptabilidad racional» o justificación, como noción normativa, no implique ninguna idealización, sino que la idealización implicada en tal noción es de una naturaleza diferente a la implicada en las nociones de «verdad» $y$ «corrección moral. Véase nota 25 . 
cncuentran una respuesta válida, su validez no se deriva del acuerdo de los participantes. Al contrario, el acuerdo de los participantes, para que sea considerado un acucrdo racionalmente motivado, ha de basarse en la satisfacción de las condiciones necesarias y suficientes ya mencionadas: los participantes tendrán que creer que el juicio en cuestión es verdadero no porque todos estén de acuerdo, sino porque expresa un estado de cosas cxistente; igualmente, si la norma en cuestión es moralmente correcta, no es porque sea aceptada por todos sino porque está igualmente en el interés de todos (lo cual es especialmente importante para distinguir un tratamiento cognitivista de un tratamiento meramente decisionista de las cuestiones morales). Habermas parece reconocer esto cuando explica en su «Reply»:

«Por un lado, son las razones sustantivas las que nos convencen de la correción del resultado; por otro lado, la sostenibilidad de dichas razones sólo puede probarse en los procesos reales de argumentación, es decir, en su defensa frente a toda objeción planteada de facto en ellos» (R, p. 1508).

A la luz de esta distinción, parcce claro que la conexión interna entre nuestras pretensiones de validez y las prácticas discursivas no nos obliga a defender la tesis contraintuitiva de que la verdad o la corrección moral significan o dependen del acuerdo argumentativo ${ }^{12}$, sino más bien a reconocer que nuestras pretensiones de verdad o de corrección moral son, al mismo tiempo, siempre

Iz En esta tesis se basan las críticas de Rawls a Habermas respecto a la distinción entre concepciones de justicia procedimentales y sustantivas en su «eply to Habermas» Ien The Joumal of Philosophy, $92 / 3$ (1995), pp. 170-180]. Rawls interpreta la ética del discurso como un intento de ofrecer una noción procedimental de justicia y da argumentos convincentes contra la plausibilidad de un intento semejante. Básicamente, Rawls argumenta que las condiciones para alcanzar un acuerdo en un discurso práctico pueden ser, a to sumo, condiciones de la legitimidad de su resultado pero no de la justicia del mismo y que, por tanto, no es la noción de justicia sino la noción más general de legitimación la que puede que sea procedimental. Aunque interpretaciones como la de Rawls se ven favorecidas precisamente por las inconsistencias -inherentes al modo en que Habermas presenta su teoría- a las que nos estamos refiriendo aquí, está claro que esta crítica de Rawls yerra el blanco de dicha teoria Como ya hemos indicado, lo que ofrece la teoria de la racionalidad comunicativa de Habermas, en realidad, es una interptetación procedimental no de la noción de «justicia» (o de «verdad») sino de la noción de «aceptabilidad racional». Esta noción no es sólo más general que las otras - como ya indica Rawls- sino que, mas importante aún, no posee un contenido especificamente moral. $Y$ ésta es precisamente la virtud y no el vicio de la construcción habcrmasiana. Una de las aspiraciones centrales de esta teoría es mostrar que tanto el desempeño de pretensiones de validez relativas a la verdad de los enunciados como el de las relativas a la justicia de las normas dependen de una y la misma concepción de aceptabilidad racional entendida en tóminos procedimentales (es decir, como resultado de una discusión que tenga lugar bajo las condiciones de una situación ideal de habla). En este sentido, la interpretación discursiva de la accptabilidad racional permite explicar simultáneamente la noción de justificación teórica y la noción de legitimación moral. Es decir, permite explicar tanto las condiciones bajo las cuales las respuestas a cuestiones teóricas sobre la verdad de los enunciados pueden considerarse justificadas como las condiciones bajo las cuales las respuestas a cuestiones prácticas sobre la justicia de las normas pueden considerarse legítimas. Sólo esta estrategia teórica permite a Habermas defender el caracter cognitivo de las cuestiones morales. Habermas explica esto mismo en "Ver- 
ya pretensiones de saber. $Y$ estas pretensiones de saber, en cuanto tales, efectivamente dependen no sólo de la verdad (o de la corrección) sino también, esencialmente, de la justificación o aceptabilidad racional.

El análisis pragmático de las pretensiones de validez implicadas en nuestras prácticas comunicativas elaborado por Habcrmas contiene efectivamente un examen de la conexión interna entre saber y aceptabilidad racional. Su análisis mucstra que a lo que nos comprometemos cuando afimamos que un determinado enunciado es verdadero (o una norma particular moralmente correcta) va, inevitablemente, más allá del mcro comprometerse con la verdad del enunciado o con la validez de la norma. Como Habermas explica en "Wahrheitstheorien»: «verdad es una pretensión de validez que vinculamos a los enunciados al afirmarlos (...). Al afirmar algo elevo la pretensión de que el enunciado que afirmo es verdadero. Esa pretensión puedo elevarla con razón o sin razón* (WI, p. 129, cursiva mía).

Lo que el análisis pragmático de la comunicación muestra es, por tanto, la inevitable interdependencia ${ }^{13}$ de dos pretensiones de validez implicadas en nuestros actos de habla: con éstos, como explica Habermas, afirmamos no sólo que el enunciado es verdadero (o la norma moralmente correcta), sino -lo que es más importante- que nosotros lo sabemos, que nuestra creencia está justificada y podríamos, si fuese necesario, desempeñar nuestra pretensión con argumentos. Precisamente por esta pretensión adicional de saber es por lo que no es suficiente, para que nucstra afirmación sea aceptable, que el juicio resulte ser verdadero o la norma correcta. Se requiere, también, que nosotros seamos capaces de justificar aquí y ahora que éste es el caso.

Es precisamente esta pretensión adicional la que nos fuerza a iniciar, en caso necesario, un discurso teórico o práctico en el que probamos nuestras pretensiones de validez. En tal discurso probamos la pretensión (nunca defi-

nüntig" versus "wahr" -oder die Moral der Weltbilder» cuando inclica: "Estoy de acuerdo con los comentarios de Rawls sobre justicia procedimental vs. sustantiva (Reply, pp. 170-180); estas reflexiones, sin embargo, no aciertan con el sentido en que uso las expresioncs "procedimiento" y "racionalidad procedimental" cuando afimo que una práctica argumentativa organizada de una determinada manera justifica el supuesto de la aceptabilidad racional de sus resultados" (en Die Einbeziehung des Anderen, Francfort, 1996, p. 119, cursiva mía).

1. Esta conexión interna entre "verdad" y uconocimiento» cs precisamente la que se pierde de vista en una explicación semántica del significado de «verdad», la cual como el deflacionismo actual deja claro- no puede obtener más que reformulaciones de la "Convención Tw. El problema no es que la "Convención $T$ ” no sea una explicación correcta del significado de kveruad", sino que nuestro interés filosófico en una explicación de la «verdad" siempre fue saber el valor epistémico de tal noción en el contexto de nuestras prácticas de formación y revisiôn de creencias. Esta perspcctiva epistémica no es accesible desde un análisis semántico de la noción de verdad en cuanto tal, sino que requiere un análisis pragmático del proceso de comunicación en el que se pone de manifiesto que nuestras pretensiones de verdad de los enunciados son al mismo tiempo siempre ya pretensiones de saber acerca de las creencias expresadas en los mismos. De csta conexión indispensable entre saber y verdad (o corrección moral) es de donde procede la concxión cntre dichas pretensiones de validez y la noción de aceptabilidad racional. 
nitivamente desempeñable) de la verdad del enunciado en cuestión (o la corrección moral de la norma en cuestión). Pero esto lo hacemos probando una pretensión de saber efectivamente desempeñable, a saber: la pretensión de que estamos justificados aqui y ahora en creer en la verdad de un determinado enunciado o en la corrección moral de una determinada norma a la luz de los mejores argumentos disponibles (también puede ocurrir que nos demos cuenta de que nuestros argumentos no son todavía lo suficientemente buenos como para decidir la cuestión de un modo u otro).

La interdependencia entre «verdad» ( 0 «corrección» moral) y «aceptabilidad racional» se hace evidente si prestamos atención a los componentes de nuestra noción de «saber». Como se expresan comúnmente, las condiciones necesarias y suficientes ${ }^{14}$ para establecer que alguien (S) sabe algo (P) son las siguientes:

$S$ sabe que $P$ si y sólo si

1) $S$ cree que $P$.

2) $P$ es verdadero.

3) S está justificado en creer que $P^{15}$.

La irreductibilidad de estas condiciones es patente: que mi enunciado sea de facio verdadero (2) no significa que yo tenga el saber que se expresa en él, es decir, que pueda dar razones de mi creencia en el mismo y que mi afirmación, por tanto, esté justificada o sea racionalmente aceptable (3). A la inversa, no es suficiente tener buenas razones que sustenten mi creencia en tal afirmación (3) para que ésta sea verdadera (2). Sin embargo, la razón de ser de esta irreductibilidad quizás no es tan evidente. Por una parte, la irreductibilidad de la verdad a la justificación o aceptabilidad racional cxpresa la validez trascendente de todo contexto de la primera en contraste con la segunda. Esta trascendencia de contexto deja abierta la posibilidad de encontrar $\rightarrow$ quizás más adelante, a la luz de nueva información, de una nueva estrategia interpretativa o incluso de una categorización enteramente nueva- un modo de defender la validez de un enunciado o norma particular que aquí y ahora parece ser completamente injustificable. Por otra parte, la irreductibilidad de la justificación a la verdad es lo que nos fuerza a probar nuestras pretensiones de verdad (o de correción moral) para que sean aceptables como justificadas $y$, por consiguiente, lo que nos obliga a retractarnos de nuestra pretensión de saber mientras no dispongamos de dicha prueba - mientras nuestras razones o justificaciones no resulten intersubjetivamente convincentes.

1: En este contexto dejo de lado las dificultades mostradas por E. Gettier en su artículo als justified true belief knowledge? , en Analysis, 23/6 (1963), pp. 121-123, pues con ellas éste se dirige a mostrar la incompletud de dichas condiciones mientras que mi argumentación se apoya exclusivamente en la indiscutida irreducibilidad de las mismas.

${ }_{15}$ Es fácil especificar estas condiciones también para el caso de la discusión sobre la *correcciónn moral de una norma. $S$ sabe que $N$ es moralmente correcta si:

1) Scree en la corrección de $\mathrm{N}$.

2) $\mathrm{N}$ es moralmentc correcta.

3) S está justificado en creer en la corrección de $\mathrm{N}$. 
Este análisis clásico de la noción de saber pone de manifiesto que no es necesario defender la tesis contraintuitiva de que la verdad de una afirmación depende de la posibilidad de acuerdo sobre ella, para defender la tesis obvia de que nuestras pretensiones de saber son dependientes de prácticas argumentativas en las que probamos la sostenibilidad de nuestras razones y argumentos exponiéndolos a la discusión pública, a todos los contraargumentos disponibles. Como explica Habermas en Teoría de la Acción Comunicativa: «los procesos de aprendizaje mediante los cuales adquirimos saber teórico y capacidad de juicio moral, revisamos y extendemos nuestro lenguaje evaluativo, superamos auto-engaños y dificultades de comprensión dependen de prácticas de argumentación» (p. 44). Pero, por esta misma razón, las prácticas argumentativas que encauzan nuestros procesos de aprendizaje pueden sólo autorizamos a mantener nuestras creencias como válidas, pero no pueden garantizar ${ }^{16}$ su «verdad» o «corrección» moral. Como ha señalado Habermas recientemente ${ }^{17}$ : «la racionalidad de un juicio no implica su verdad sino sólo su aceptabilidad racional en un contexto dado" (KR, p. 69). Parece, por tanto, que para defender la idea de que las pretensiones de saber ${ }^{18}$ son dependientes de la aceptabilidad racional (así como de la verdad o de la corrección moral), no es necesario mantener la posición contraintuitiva de que la verdad y la corrección moral mismas son dependientes de la aceptabilidad racional.

La intuición central de la interpretación de la aceptabilidad racional en términos de la ética del discurso parece ser la siguiente: en la medida en que no podemos tener acceso directo a la verdad (o a la realidad en sí misma), sólo nos queda la posibilidad de inferir la verdad de nuestras creencias de la sostenibilidad de nuestras razones. Así pues, alguien está justificado en creer algo si sus razones son (o resultaran ser) convincentes para todos e injustificado si sus razones son meramente subjetivas o idiosincráticas. Por consiguiente, si la teoría del discurso es correcta, sólo podemos inferir la sostenibilidad de nuestras razones de los resultados de un proceso discursivo que tuviera lugar en una situación ideal de habla. La justificación o aceptabilidad racional

in Precisamente el hecho de que no hay tal garantía se refleja en nuestra comprensión de la noción de «saber» como dependiente de tres condiciones necesarias analíticamente independientes, es decir, en el hecho de que no pueda considerarse ninguna de ellas, por sí misma, como condición suficiente para el saber. Sólo gracias a esta comprcnsión podemos mantener una actitud falibilista con respecto a cualquier creencia candidata a saber.

12 J. Habermas, «Sprechakttheoretische Erläuterungen zum Begriff der kommunikativen Rationalitäts (KR), Zeitschrift für Philosophische Forschung, 50/1-2 (1996), pp. 65-91.

"I I dimensión epistémica de la "validez para nosotros" (R, p. 1509) que Habermas quiere retener no se origina en el hecho de que la verdad o la corrección moral sean dependientes de nucstros juicios y acuerdos, sino en el hecho de que el saber está inevitablemente ligado a nosotros. Esta obvia circunstancia es expresada en la primera de las tres condiciones del saber: para que yo sepa algo, yo tengo que creerlo. "Saber" (a diferencia de kverdad") sólo puede ser saber para nosotros. Pero, por esta misma razón, la trascendencia de todo contexto implicita en la validez absoluta de la verdad (o de la corrección moral) no debería buscarse en la dimensión epistémica de la «validez para nosotros». 
en este sentido intersubjetivo es esencial, por tanto, para nuestras prácticas epistémicas en tanto que nos permite distinguir entre modos razonables y modos no razonables de adquirir conocimiento. Ésta es la razón por la que una «creencia verdadera" no es considerada automáticamente como «saber»" ${ }^{19}$, puesto que «sabcr» implica también una evaluación de la fiabilidad del modo en el que se adquiere (y justifica) la creencia en cuestión. Para dar cabida a la posibilidad (más que probable) de un error general ${ }^{20}$ (y del consiguicnte proceso de aprendizaje y corrección), para que no se olvide que la inferencia antes mencionada puede fallar, es escncial evitar la identificación de kcreencia justificada» y «saber». Ésta es la razón por la cual en nuestra noción de «saber» se rcconoce la independencia lógica entre justificación y verdad (o corrección moral).

Uno de los factores esenciales que imposibilita la identificación de la verdad de una afirmación (o la corrección moral de una norma) con la aceptabilidad racional de la misma es la validez incondicional que atribuimos a la primera pcro no a la segunda. Esta diferencia se remonta a dos rasgos característicos de nuestro uso de la noción de «verdad» (o de «corrección» moral) - rasgos que no se pueden encontrar en el uso de la noción de justificación (o aceptabilidad racional) - : primero, el uso binano de la oposición verdadero/falso (o justo/injusto) en contraste con el uso gradual de la noción de justificación y, segundo, el carácter fijo que atribuimos a la verdad (o a la corrección moral) en contraste con la justificación o la aceptabilidad racional, es decir, el hecho de que la verdad o la corrección moral son consideradas propiedades que las afirmaciones o las normas no pueden perder.

La combinación de estos dos rasgos es precisamente la que da como resultado la «premisa de "una única respuesta correcta"»: no podemos decir que una afirmación cra verdadera y ahora es falsa, o que una norma era justa y ahora es injusta. Esto explica por qué no podemos decir que sabiamos algo que resultó ser incorrecto, mientras que podemos decir, sin contradicción alguna, que estabamos justificados -es decir, que éramos epistémicamente responsables - al creer algo que resultó ser falso (o moralmente incorrecto).

15 La intuición de que la verdad no puede ser condición suficiente para el saber es el único modo de evitar que el adivino pueda ser considerado como conocedor de la verdad, incluso en el caso de que algunas de sus afirmaciones resulten ser verdaderas.

tr Por ejemplo, el caso cn el que (visto retrospectivamente) no habia nada particularmente idiosinctático en nuestras razones pero tenímos simplemente la categorización equivocada de la cucstión cn gcneral, o careciamos de la creatividad abductiva requerida para elaborat un paradigma explicativo correcto capaz de producir enunciados verdaderos (como en casos en los que el resultado de un proceso de aprendizaje no es la corrección interna de los argumentos disponibles en una explicación o teoria particular sino un cambio de paradigma). En tal caso nuestras antiguas crencias no se consideran injustificadas en el sentido de que nuestras razones para sustentarlas no fuesen convincentes (es dccir, cn cl sentido de que no estabamos siendo epistémicamente respomables o racionales), sino sólo en el sentido de que nuestras razones eran incorrectas oinsuficientes para establecer la verdad. Para un examen de estos dos sentidos diferentes de justificación, véase R. Fogelin: Pymonhian Reflexions on Knowledge and Justification, New York, 1994, pp. 24 y ss. 
Esta imposibilidad es precisamente lo que sugicre la trascendencia de contexto de la validez de tales nociones absolutas.

Sin embargo, si intentamos explicar esta trascendencia de contexto apelando a la noción de «aceptabilidad racional en condiciones ideales», nos vemos obligados a transferir la validez incondicional de la «verdad" (o de la "corrección moral») a la noción epistémica de «aceptabilidad racional en condiciones ideales». Al hacer esto, tenemos que considerar nuestras interpretaciones y modos particulares de justificar los enunciados que mantenemos como verdaderos (y las normas que mantenemos como moralmente correctas) como dotados también de una validez absoluta. Nuestra cvaluación ticne entonces también que ser considerada como constreñida por el uso binario característico de la noción de «verdad» (o de la noción de «corrección» moral), es decir, por el tertium non datur implícito en la premisa de «una única respuesta verdadera»: así como tenemos que presuponer que «si una afirmación es verdadera no puede ser falsa al mismo tiempo», tenemos que aceptar que «si una afirmación es racionalmente aceptable en condiciones ideales no puede ser falsa al mismo tiempo» ${ }^{21}$. La consecuencia de eliminar la independencia lógica entre la verdad y la aceptabilidad racional - aunque sólo sea contrafácticamente- es que, en tal caso, no sólo es válido que si una afirmación es verdadera no puede ser falsa sino también que nuestro modo particular de justificar la afirmación no puede estar equivocado tampoco. Así pues, la interpretación (o teoría) particular a través de la cual comprendemos y justificamos la verdad de una afirmación tiene que ser absolutamente correcta, la única interpretación correcta. Es en este sentido en el que la noción de «aceptabilidad racional en condiciones ideales» parece implicar, inevitablemente, la anticipación de un final del proceso de argumentación: así entendida, la pretensión de aceptabilidad racional para nuestras razones y argumentos supone anticipar - al menos desde la perspectiva de los participantes - que dichas razones y argumentos «se sostendrán frente a todas las objeciones posibles» (R, p. 1508). Por tanto, estas razones se encuentran entre las definitivas, se derivan de la única interpretación correcta ${ }^{22}$. En

$\because$ En «Realism and Reason» (Meaning and the Moral Sciences, Londres, 1978, pp. 123-140), Putnam explica la conexión interna entre dicha noción de «aceptabilidad racional en condiciones ideales» y la idea de «una verdad absolutamente "irrevisable" como idealización» (p. 138), cuando indica: «La suposición de que incluso una teoría "ideal" (...) pudiera en realidad ser falsa parece colapsar en una pura ininteligibilidad" (p. 126). Putnam recientemente ha rechazado csta concepción epistémica de la verdad (como «aceptabilidad racional en condiciones idealesw) precisamente por sus consecuencias antifalibilistas [véase "Comments and Replies», en P. Clark y B. Hale (eds.), Reading Punam, Cambridge, Mass., 1994, pp. 242-295].

"Si ése fuese efectivamente el compromiso que contraemos al elevar pretensiones de validez respecto a nuestras creencias nunca nos atreveriamos a afirmar la aceptabilidad racional de las mismas $(y$, por consiguiente, no seríamos capaces de distinguir entre responsabilidad e irresponsabilidad epistémica, entre justificaciones válidas e inválidas). Habermas parece reconocer esto cuando señala: «Quien comparte opiniones que resultan ser falsas no es, por ello, irracional; irtacional es quien mantienc sus opiniones dogmáticamente, se aferra a ellas, a pesar de ver que no puede justificarlas. Para que una opinión pueda calificarse de racional es suficiente que 
este sentido, la aceptabilidad racional está relacionada, no con nuestra capacidad de razonar en una situación ideal de habla (es decir, con nuestra capacidad de ser epistémicamente responsables), ni con el procedimiento de la argumentación, sino con su contenido. Obviamente, si lo que es racionalmente aceptable en condiciones idcales posee también la validez absoluta que atribuimos a la «verdad» y a la «corrección» moral, nuestro compromiso con la racionalidad es inevitablemente un compromiso con la incorregibilidad.

Esta estrategia sugiere ciertamente que aceptar la premisa de «una única respuesta correcta" implica aceptar un compromiso epistémico adicional con la premisa de «una única interpretación correcta». Pero precisamente a causa de este compromiso epistémico, las dificultades de esta estrategia van más allá de una mera explicación contraintuitiva del significado de «verdad» y «corrección» moral. Estas dificultades atañen al problemático paso de introducir idealizaciones antifalibilistas en la noción de aceptabilidad racional.

Sin embargo, si prestamos atención a nuestro uso de la noción de aceptabilidad racional (en contraste con nuestro uso de nociones como «verdad», "corrección» moral o "saber»), nos damos cuenta de que éste no implica realmente validez incondicional alguna: admite un uso gradual y está abierto a cambios en el tiempo (en contraste con el uso binario de nociones como «saber", «verdad» o «corrección» moral, para los que presuponemos un valor fijo). Es importante recordar lo cabalmente racional de tal uso: si queremos ser capaces de desempeñar nuestra pretensión de estar justificados en un momento dado, sólo podemos comprometernos a ser razonables -en el sentido de que nuestras razones han de ser convincentes para todos como las mejores razones disponibles- pero no a tener éxito - a que nuestras razones resulten además capaces de establecer la verdad- ${ }^{23}$. Como explica Habermas en su «Entgegnung" ${ }^{24}$ : «que nuestras razones realmente son buenas razones y bastan para cerciorarnos de la verdad no cambia para nada el hecho de que, en principio, aquello que consideramos como - definitivamente- verdadero podría resultar alguna vez ser un error» (p. 352).

Cuando afirmamos que nuestras creencias están justificadas, a lo que nos comprometemos no es a tener las razones o los argumentos últimos, definitivamente correctos. Al contrario, siempre que mantenemos la aceptabilidad

pueda ser tenida por verdadera en base a buenas razones en un contexto de justificación determinado, es decir, que pueda ser considerada racionalmente aceptable» (KR, p. 69).

${ }^{3}$ Si siempre que elevâramos pretensiones de validez presupusiéramos -aunque fuese desde la perspectiva interna de los participantes en el proceso de comunicación- que tenemos los argumentos correctos, que no sólo somos racionales sino, además, exitosos, no tendriamos ninguna razón para iniciar un discurso o para adoptar una actitud hipotética con respecto a nuestras creencias. El rechazo de tal presuposición fundamentalista (en sociedades post-tradicionales) es precisamente lo que hace posible la nocion procedimental de aceptabilidad racional, como la teoría del discurso explica.

* J. Habermas, "Entgegnung", en A. Honneth, T. McCarthy et al. (eds.), Kommumikativen Handeins, Francfort, 1986, pp. 327-40s. 
racional de nuestras creencias, confiamos en nuestra responsabilidad cpistémica y no en una - misteriosa - garantía de éxito. Nuestro compromiso, por tanto, sólo implica que nuestras razones pueden (o podrían) ser consideradas por todos como buenas razones - por supuesto, mientras no aparezca ningún contraargumento (o ninguna evidencia en contra, etc.) - . Para probar la solidez de nuestros argumentos, nos comprometemos a presentarlos ante todos los participantes posibles en un discurso, a adoptar una actitud hipotética respecto a su validez y a seguir, exclusivamente, la lógica de sla coacción sin coacciones del mejor argumento*. Estos compromisos ponen de manificsto el contenido normativo (o idealizado) de la noción de justificación o aceptabilidad racional. El uso de tal noción sólo tiene sentido bajo la presuposición de que, si todas estas condiciones se cumplen (es decir, en una situación ideal de htbla), «la coacción sin coacciones del mejor argumento» sería una coacción universal ${ }^{25}$; es decir, en palabras de Hahermas ${ }^{26}$, que atoda persona que participa en prácticas argumentativas en general puede llegar en principio a los mismos juicios sobre la aceptabilidad de las normass (p. 131) -o de los enunciados-.

La noción de «justificación»o «aceptabilidad racional» (en su sentido intersubjetivo) parece concernir la solidez de nuestros procedimientos de adquisición de conocimientos, no el carácter absoluto de un contenido último (hipostatizado). Por eso, para que la noción de «aceptabilidad racional» pueda resultar realmente operativa en la evaluación de nuestros procesos argumentativos (de lo que puede considerarse como válido para nosotros en un momento determinado) no debe sobrecargarse con la validez incondicional característica de nociones como "verdad", xcorrección» moral o usaber».

La cuestión parece radicar, pues, en cómo explicar la validez incondicional de estas nociones, de la que depende la corrección de la premisa de auna única respuesta correcta", sin apelar - ni siquiera contrafácticamentc- al carácter absoluto de la presuposición de «una única interpretación correcta». En mi opinión, todos los elementos necesarios para tal explicación pueden ya encontrarse en el análisis de la racionalidad comunicativa del propio Habermas.

Como señalamos antes, la validez incondicional o absoluta implícita en el uso binario de nociones como «verdad» ( $y$ «corrección» moral) puede explicarse como consecuencia de una condición trivial: si una afirmación es verdadera no puede ser falsa al mismo tiempo. Al usar la oposición verdadero/falso (y

${ }^{3} \mathrm{O}$, dicho en otras palabras, que en tales condiciones todos los participantes cyaluarian la tuerza de los argumentos del mismo modo. Obviamente el uso de una noción como uaceptabilidad racionals implica la posibilidad de una conyergencia transcultural en nuestros criterios de racionalidad. El universalismo implicito en tal presuposición de la unidad de la nazón puede considerarse ya polémico de por sí, pero al menos no tanto como lo sería si tuviese que apoyar también la presuposición adicional del éxito necesario de nuestra razón. Nuestras intuiciones falibilistas nos enseñan que no hay tal garantia de éxito.

36 J. Habermas, «Moralbewußtscin und kommunikatives Handeln», en Morabewußssein und kommunikatives Handeln, Francfort, 1983, pp. 127-206. 
lo mismo es válido también para la «corrección» moral o el «saber»), nos comprometemos a aceptar que la afirmación en cuestión es o bien verdadera o bien falsa $\mathrm{y}$, por tanto, que nuestra evaluación de las razones que apoyan tal afirmación tendrá que llevar a la exclusión de una de las dos posibilidades. Esta condición lógica parece ser una consecuencia de las presuposiciones de existencia antes mencionadas implicitas en el significado de las nociones de verdad y corrección moral: la verdad de una afirmación depende de si el estado de cosas descrito existe y la corrección moral de una norma de si las acciones reguladas cstán en el interés de todos.

Debido a estas presuposiciones de existencia, cada vez que usamos tales nociones binarias tenemos que aceptar - de antemano - la validez de la premisa de «una única respuesta correcta». Pero precisamente porque estas presuposiciones de existencia no tienen ningún contenido epistémico, nuestro compromiso con la premisa de uuna única respuesta correcta»-y por lo tanto con la validez trascendente de todo contexto de estas nociones- no incluye una consecuencia epistémica como la de la premisa de «una única interpretación correcta». Es decir, este compromiso no predetermina de cuántas formas epistémicas seremos capaces de expresar la existencia de los mismos estados de cosas o de salvaguardar los mismos intereses universalizables. En este sentido, la premisa (lógica) de «una única respuesta correcta» no implica per se la premisa (epistémica) de «una única interpretación correcta».

A continuación voy a intentar mostrar, usando los argumentos de Putnam, cómo este pluralismo epistémico, que parece sostenible en relación con las cuestiones teóricas sobre la verdad, puede aceptarse análogamente para las cuestiones prácticas relativas a la corrección moral.

El debate que Putnam sostiene con B. Williams en Realism with a Human Face $^{27}$ puede ser reformulado para nuestros propósitos como un intento de poner de manificsto que, para defender la justificación de la premisa de «una única respuesta correcta», no necesitamos introducir la presuposición de «una única interpretación correcta» o -en términos de Putnam- de una «concepción absoluta del mundo».

En su defensa de esta tesis Putnam apela al estado actual de las ciencias empíricas:

*En el contexto de la geometría espacio-temporal nos encontramos con el hecho bien conocido de que los puntos pueden ser interpretados como individuos o bien como meros límites. Los estados de un sistema pueden ser interpretados como super-

"Vcase H. Putnam, Realism with a Human Face (RHF), Cambridge, Mass,, 1990, capitulo 11; especialmente la sección titulada *Absoluteness», pp. 170-174. 
posiciones de la mecánica cuántica de las interacciones de partículas (...) o bien como superposiciones de la mecánica cuántica de estados de campos. (...) No sólo es el caso que teorias únicas tienen una desconcertante variedad de reconstrucciones racionales alternativas (con ontologías bastante diferentes), sino que además no hay evidencia alguna (...) de que la ciencia converja en una teoría unica. (...) Que la convergencia en una única concepción (one big picture) es requerida por el concepto mismo de saber es puro dogmatismo. No obstante, sin el postulado de que la ciencia converge en una concepción teórica particular y única, con una única ontología y un único conjunto de predicados teóricos, la idea misma de una concepción "absoluta" se derrumbà $\left(\right.$ RHF, p. 171) ${ }^{2 k}$.

Si esto es correcto, defender la premisa de «una única respuesta correcta» no parece requerir la aceptación de la presuposición epistémica de «una única interpretación correcta». Sólo tenemos que ser capaces de reconocer, a través de las diferentes ontologias contenidas en las diferentes teorias o interpretaciones en cuestión, que estas interpretaciones alternativas son interpretaciones de los mismos fenómenos y, por tanto, que los valores de verdad de las afirmaciones - en este sentido, equivalentes- tendrán que ser distribuidos a través de estas conceptualizaciones o interpretaciones alternativas del mismo modo. Como lo expresa Putnam en Renewing Philosophy ${ }^{29}:$ :Si un juicio cs verdadero en una versión, entonces su correlato en la otra versión es verdadero en dicha versións (p. 118). Este requisito, derivado de lo que Putnam denomina la "útil idealización" del "principio de bivalencia» (p. 123), subyace a nuestro uso de la oposición verdadero/falso. Sin embargo, esto no ha de entenderse como si los enunciados de dos teorías diferentes, para ser equivalentes, tuvieran que ser (trivialmcnte) sinónimos, como si no fuesen - por así decirlo- formas genuinamente alternativas de conceptualizar los mismos fenómenos -como si fuesen al fin y al cabo una única teoría- Como muestra Putnam, tales enunciados no son sinónimos en absoluto. No pueden preservar el significado puesto que sólo adquieren su significado en el contexto holista de sus respectivas teorías o conceptualizaciones y éstas, efectivamentc, no pueden ser reducidas a una: «Pero preguntar si estos dos enunciados tienen el mismo significado es intentar forzar la noción de significado del lenguaje ordinario a desempeñar una tarea para la cual no fuc nunca concebida. (...) Deberíamos simplemente abandonar la idea de que los enunciados que hemos estado discutiendo preservan algo que podamos llamar su "significado" cuando pasamos de una versión a otra» (p. 119). Como Putnam pone de manifiesto más adelante, lo que realmente se preserva es la referencia: «Palabras aparentemente incompatibles pue-

2* Putnam continúa su argumentación derivando consecuencias para el saber ético en los siguientes términos: «Sin duda es el caso que el saber ético no puede pretender carácter absoluto; pero esto es porque la noción de una concepción absoluta es incoherente. La matemática y la fisica, así como la ética, la historia y la política, reflejan nuestras clccioncs conceptuales; el mundo no va a imponernos un único lenguaje, sea lo que fuera sobre lo que escojamos hablar» (ibid., p. 117).

H. Putnam, Renewing Philosophy, Cambridge, Mass., 1992. 
den en realidad describir la misma situación, el mismo hecho o el mismo sistema físico» (p. 124).

Sólo al tener en cuenta esta posibilidad es posible reconocer la falacia de considerar la premisa epistémica de «una única interpretación correcta» como necesariamente contenida en la premisa de «una única respuesta correcta». Así pues podemos reconoccr que cl pluralismo epistémico no implica necesariamente relativismo. Como señala Putnam: «El hecho de que el sistema real permita que se hable de él de estas dos formas diferentes no quierc decir ni que no haya un sistema físico real del que se hable, ni que haya dos sistemas físicos diferentes en dos mundos goodmanianos distintos de los que hablamos. (...) Es absolutamente claro, en mi opinión, que las dos descripciones son descripciones de uno y el mismo mundo, no de dos mundos diferentcs» (p. 122). Putnam concluye: «La idea central (...) es que enunciados muy diferentes pueden describir el mismo estado de cosas» (p. 117).

Es esta posibilidad la que lleva a Putnam a extraer la conclusión adicional de que tenemos «que reconocer que hay muchas descripciones verdaderas del mundo en muchos vocabularios diferentes, sin intentar privilegiar una de esas decripciones como la "absoluta"» (p. 103). En la medida en que podemos "afirmar que nuestros esquemas conceptuales son simplemente "descripciones" diferentes de lo que en cierto sentido son "los mismos hechos" $(p, 110)$-lo cual es siempre una afirmación revisable-, podemos conceder que uno hay una única descripción verdadera de la realidad» (ibid.), es decir, podemos abandonar la dudosa presuposición de una «concepción absoluta del mundo».

Para mantener tal afirmación no es necesario postular la posibilidad de tener acceso directo a la realidad en sí misma. Al contrario, sólo necesitamos ser capaces de reconocer conceptualizaciones diferentes como conceptualizaciones de los mismos fenómenos. Habermas explica en su "Reply» lo que esta capacidad implica en los siguicntes términos:

«Si queremos hacer justicia al hecho trascendental del aprendizaje tenemos que contar, efectivamente, con una razón comunicativa que ya no prejuzga los contenidos de una visión particular del mundo. Esta razón enteramente procedimental opera con pretensiones de validez trascendente de todo contexto y con presuposiciones pragmáticas sobre el mundo. Pero la presuposición de un mundo objetivo que es el mismo para todos los participantes en la comunicación sólo tiene el significado formal de un sistema de referencia ontológicamente neutral. No implica más que el hecho de que somos capaces de referirnos a las mismas entidades, reidentificarlas, aun cuando nuestras descripciones de las mismas cambian» ( $R$, p. 1527).

La conexión entre esta capacidad formal y la posibilidad de aprendizaje se pone de manifiesto si tenemos en cuenta que tal capacidad es condición de posibilidad del discurso en cuanto tal. Esta capacidad es lo que se requiere para evaluar la aceptabilidad racional de interpretaciones alternativas en un discurso teórico, puesto que es precisamente la capacidad que permite a los 
participantes en un discurso adoptar una actitud hipotética sobre sus propias interpretaciones y conceptualizaciones. Como explica Habermas en Teoría de la Acción Comunicativa:

«Las pretensiones de validez resultan en principio susceptibles de critica porque se apoyan en conceptos formales de mundo. Presuponen un mundo idéntico para todos los observadores posibles o un mundo intersubjetivamente compartido por todos los miembros de un grupo, y ello en forma abstracta, es decir, desligada de todos los contenidos concretos» (Theorie des kommunikativen Handelns, Francfort, 1981, vol. 1, p. 82).

Si reconoccmos el carácter formal de estas presuposiciones de existencia, podemos ver que la premisa de «una única respuesta correcta» que se deriva de cllas no incluye ninguna presuposición epistémica de carácter absoluto para los contenidos particulares en cuestión; es decir, no implica la premisa de «una única interpretación correcta». Pero, por esta misma razón, estas presuposiciones formales de existencia, en tanto que constituyen una condición de posibilidad del discurso en general, son operativas tanto en discursos teóricos como prácticos.

El contenido particular del sistema formal de referencia (o de la presuposición de existencia) ligado al discurso práctico es, por razones obvias, diferente del operativo en discursos teóricos. Pero su rol formal, en tanto que condición de posibilidad del discurso, es en realidad el mismo. Así como la presuposición de la existencia de estados de cosas en el mundo objetivo es la condición de posibilidad para una discusión con sentido sobre la verdad de los enunciados, la presuposición de existencia de intereses universalizables compartidos por todos los miembros del mundo social es la condición de posibilidad para una discusión con sentido sobre la corrección moral de las normas sociales. Esta presuposición de existencia es indispensable para el discurso práctico no porque sea necesariamente el caso que existen tales intereses compartidos por todos los seres humanos, sino porque si llegásemos a la conclusión de que csta presuposición carece de sentido (lo cual es, obviamente, una cuestión empírica abierta), la discusión sobre la corrección moral de las normas sociales dejaría igualmente de tener sentido. Como señala Rousseau en El Contrato Social (Oxford, 1994):

«Si bien es cierto que el establecimiento de sociedades se hizo necesario porque los intereses individuales estaban en conflicto, también es cierto que se hizo posible porque esos intereses concurren. El vínculo social está formado por lo que estos intereses tienen en común; si no hubiese algún punto en el que todo interés coincide, ninguna sociedad podría existir. Y es sólo sobre la base de este interés común que la sociedad puede ser gobernada» (p. 63, cursiva mía).

O expresado en términos de la ćtica del discurso: si, como pura cuestión de hecho, no hubiera una esfera de intereses irrenunciables comunes a todos 
los seres humanos, no entenderíamos to que significa considerar una norma moralmente correcta o incorrecta (justa o injusta). Pero en la medida en que podemos presuponer razonablemente que hay tales intereses comunes entre los seres humanos, en la medida en que tiene sentido para nosotros buscar qué normas están «igualmente en el interés de todos», sólo puede haber una única respuesta correcta, es decir, respecto a toda norma es válido que o bien salvaguarda dichos intereses o no lo hacc.

Al igual que en el caso de las cuestiones sobre la verdad, mantener el compromiso que se contrae con el uso de la oposición binaria «moralmente correcto/moralmente incorrecto» en la evaluación de normas sociales sólo requiere que los participantes en un discurso práctico, con la ayuda de sus propias interpretaciones - quizás diferentes - de los intereses comunes, intenten alcanzar un consenso sobre la corrección moral de la norma en cuestión. Este acuerdo, sin embargo, no es dependiente de un acuerdo previo sobre las interpretaciones respectivas de las razones por las cuales los intereses salvaguardados por la norma son considerados irrenunciables, dignos de ser preservados, inalienables o lo que sea el caso.

El argumento de McCarthy contra la validez de la premisa de «una única respuesta correcta» tiene fuerza sólo si asumimos que esta premisa implica necesariamente la premisa de «una única interpretación correcta». El argumento central parece ser que, en la medida en que el acceso a nuestros propios intereses y necesidades está simbólicamente (es decir, culturalmente) mediado, siempre que nuestras descripciones $c$ interpretaciones de estas necesidades e intereses son diferentes (en cualquicr medida), tenemos que concluir que no pueden ser descripciones o interpretaciones diferentes de los mismos intereses y necesidades, que no hay modo alguno de considerar dichas necesidades, simbólicamente interpretadas, como las mismas necesidades en las distintas interpretaciones alternativas. Sólo si los participantes en un discurso práctico no tuviesen esta posibilidad a su alcance, sólo si opcrasen bajo la premisa de «una única interpretación correcta», el pluralismo de las interpretaciones éticas (característico de las socicdades multiculturales) los llevaría, inevitablemente, a aceptar el relativismo.

Habermas parece ${ }^{30}$ ver csto cuando en su respuesta a la crítica de McCarthy en Erläuterungen zur Diskursethik señala:

${ }^{4}$ Habermas parece reconocer el sentido no epistémico de la premisa de uuna única respucsta correcta» en diferentes puntos de su «Reply", por cjemplo cuando dice; "Si distintas constituciones nacionales reptesentan otras tantas interpretaciones históricas de los mismos derechos fundamentales - teóricamente reconstruibles-y y i distintos ordenamientos jurídicos positivos implementan los mismos derechos fundamentales en las formas de vida correspondientes, la identidad del sentido de dichos derechos y la universalidad de su contenido no puede disolverse en el espectro de dichas interpretaciones diferentes» (R, p. 1498).

Pero en su uso de la expresión «identidad de sentido» se esconde la premisa epistémica de «una única interpretación correcta», como se pone de manificsto cuando continúa diciendo: «Esta disputa de interpretaciones sólo tiene sentido bajo la premisa de que hay que encontrar 
«Cómo de extensa es la esfera de intereses estrictamente universalizables continúa siendo una cuestión empirica. Sólo si pudiera mostrarse que, a pesar del creciente consenso - en torno a derechos fundamentales y democracia, por cjemplo-, los discursos morales han de resultar, por principio, estériles porque no es posible en absoluto identificar intereses comunes a travês de lenguajes inconmensurables, fracasaría el intento de defender desde un planteamiento deontológico la autonomia (Entkoppelung) de las cuestiones de justicia respecto a las cuestiones de la buena vida, siempre dependientes de contexto» (EDE, pp. 202-203).

Sin embargo, si concedemos la posibilidad de identificar las mismas necesidades e intereses incluso bajo interpretaciones (relativamente) diferentes, no resulta ya claro que la premisa de «una única respuesta correcta» requiera presuponer «la premisa de que hay que cncontrar una única interpretación correcta" ( $R$, p. 1498). El único requisito parece ser que, independientemente de los diferentes modos culturales de entender e interpretar históricamente estos intereses y necesidades, los participantes en discursos prácticos sean capaces de alcanzar un acuerdo sobre las normas que han de ser consideradas como moralmente correctas en tanto que salvaguarden los intereses comunes, inalienables que todos resulten tener-. En la medida en que los participantes encuentren factible identificar tales intereses comunes, tiene sentido - aunque sea quizás extremadamente difícil- buscar un acuerdo sobre las normas sociales que pueden ser consideradas como moralmente correctas (incluso si se aceptan los modos plurales de articular estos intereses comunes en culturas diferentes). La tarea hermenéutica que se requiere de los participantes en discursos prácticos, a saber, que sean capaces de salvar la distancia entre interpretaciones diferentes e identificar la misma esfera de intereses inalienables, incluso bajo conceptualizaciones alternativas, es ya suficientemente dificil ${ }^{31}$. Pero sería directamente imposible si los participantes tuviesen, además, que alcanzar un acuerdo sobre el modo particular de interpretar y entender los intereses en cuestión.

una interpretación correcta que agote el contenido universalista de dichos derechos en el contexto presenten (ibid.).

La tesis de que la identidad de contenido de los derechos humanos deriva de un sentido (o interpretación de csos derechos) ideal e idéntico, que espera a ser descubierto, me parece dudosa. En mi opinión, la identidad de contenido de los derechos humanos depende más bien de su referencia a los intereses presupuestos como existentes en todos los seres humanos. Eso es simplemente lo que se quiere decir cuando decimos que diferentes interpretaciones pueden expresar los mismos intereses.

"Obviamente no tanto como puede parecer. Sería imposible si tuviese que tener lugar a este nivel abstracto, si tuviera que tratarse de un acuerdo moral general -definitivo- sobre las interpretaciones alternativas admisibles de los intereses universalizables (frente a las inadmisibles). El hecho de quc los discursos prácticos se centren en normas sociafes (en acciones permitidas y prohibidas) da a los participantes un modo operacional (relativamente independiente) de identifficur sus propios intereses atendiendo a las consecuencias del cumplimiento general de la norma en cuestión, como pone de manifiesto la interpretación discursiva de "U». Precisamentc porque csta identificación no está determinada de una vez por todas -especialmente en la medida en que ha de tener lugar a través de interpretaciones culturales diferentes- la decisión sobre 
Pero incluso si se reconoce el contenido formal (no epistémico) de la premisa de «una única respuesta correcta», hay un aspecto más implicado en la discusión sobre el cognitivismo implícito en tal premisa que queda por dilucidar. La línea entre pluralismo y relativismo ha de trazarse de modo más preciso.

Como ya conocemos por la defensa que Habermas ofrece del cognitivismo implícito en la ética del discurso, la premisa parece implicar el requisito adicional de que los participantes en un discurso práctico han de estar de acuerdo en la corrección moral de una norma por las mismas razones. En mi opinión esto es correcto, pero tengo la impresión de que hay una ambigüedad en esta formulación que hace difícil distinguir entre la premisa de «una única respuesta correcta» y la premisa de «una única interpretación correcta». Sin embargo, en este contexto tal distinción parece ser crucial para la defensa que Habermas pretende de la autonomía (Entkoppenlung) de las cuestiones morales, de justicia, con respecto a las cuestiones éticas.

El requisito en cuestión puede ser entendido de dos modos muy diferentes. En mi opinión, uno de estos modos es importante para la teoría del discurso; el otro, en cambio, es lo que provoca la crítica del carácter absoluto de la premisa de «una única interpretación correcta». Al igual que esta premisa, en mi opinión, el segundo modo de entender tal requisito no se encuentra entre las presuposiciones normativas propias de un punto de vista universalista o cognitivista. Este modo de entender el requisito parece implicar que los participantes en un discurso práctico pueden llegar a conclusiones compartidas sólo si comparten los trasfondos evaluativos o las autocomprensiones éticas de los que extraen sus razones para la justificación de las normas morales. En sociedades multiculturales, sin embargo, no es probable que los participantes en discursos prácticos compartan dichos trasfondos evaluativos. Se sigue, por tanto, que en discusiones sobre si una norma está «igualmente en el interés de todos", aun en el caso en que los participantes lleguen a conclusiones comuncs, no lo harán por las mismas razones.

Sin embargo, a mi modo de ver, una perspectiva universalista 0 cognitivista sobre cuestiones morales no descansa en una interpretación tan fuerte (o sustancial) de dicho requisito. Una perspectiva tal requiere solamente:

- que todos los participantes estén de acuerdo en la corrección o incorrección moral de la norma en cuestión, $y$

- que, por lo tanto, todos ellos den su asentimiento a la validez de la norma por la razón de que la norma es moralmente correcta, es decir, preserva un interés universalizable, está «igualmente en el interés de todos» (lo cual

la corrección moral de una norma depende de la posible aceptación de todos los afectados por ella. 
contrasta con que sea un buen compromiso o una regulación eficiente, por ejemplo).

Este primer nivel de acuerdo sólo expresa lo que significa que una norma sea justa; en este sentido es idéntico al requisito indispensable de que los participantes en un discurso práctico tienen que ser capaces de adoptar el punto de vista moral. Pero más allá de este nivel de consenso no es necesario que estén de acuerdo también en las adicionales razones sustantivas de por qué los intercses o necesidades regulados por la norma son dignos de ser salvaguardados, inalienables (o lo que corresponda en cada caso). El universalista o cognitivista reconoce, efectivamente, que el valor de las regulacioncs sociales moralmente correctas sólo puede entenderse desde la perspectiva interna de una autocomprensión ética. Tal perspectiva, como marco interpretativo a través del cual los participantes toman conciencia de sus propias necesidades e intereses, es una condición necesaria para la participación en un discurso práctico. Sin embargo, los participantes no necesitan compartir estos marcos interpretativos, pues pueden llegar a un acuerdo sobre si la norma en cuestión preserva los intereses que todos ellos resultan tener, incluso aunque describan e interpreten dichos intereses recurriendo a construccioncs simbólicas diferentes contenidas en tradiciones culturales distintas.

En realidad, la ética del discurso excluye la presuposición absoluta de que los participantes no pueden llegar a un acuerdo sobre la corrección moral de una norma particular (evaluando si preserva un interés universalizable o no) si no se ponen de acuerdo, al mismo tiempo, en el modo particular de entender estos intereses en general. Esta presuposición queda excluida precisamente en la medida en que se defiende la autonomía (relativa) de las cuestiones morales, de justicia, con respecto a las cuestiones éticas.

Pero, por csta misma razón, parece que sólo es posible mantener un pluralismo epistémico de interpretaciones, sin caer en un punto de vista relativista, si explicamos nuestra intuición universalista sobre la validez incondicional de la "corrección» moral de las normas sociales en términos de la existencia de una esfera de intereses universalizables, comunes a todos los seres humanos. Porque ( $y$ en la medida en que) hay una esfera tal, podemos en principio encontrar normas capaces de preservar estos intereses; sólo estas normas pueden ser consideradas moralmente correctas. El carácter binario de la oposición absoluta «moralmente correcto/moralmente incorrecto» no tiene por qué extenderse, sin embargo, más allá de las normas en cuestión, a las interpretaciones mismas a la luz de las cuales los participantes comprenden sus propias necesidades $\mathrm{e}$ intereses.

Como se señaló antes, la presuposición de una esfera de intereses comunes es inevitable sólo en la medida en que, sin ella, no tiene sentido alguno intentar determinar si una norma está «igualmente en el interés de todos» o no. En este sentido, la cuestión no parece ser si nuestras pretensiones de corrcción moral implican tal presuposición, pues los participantes no parecen tencr tal 
elección. La cuestión parece ser, más bien, si los participantes tienen que presuponer no sólo la existencia de tales intereses comunes (como quiera que sean interpretados), sino también que, entre los diferentes modos de entender estos intereses por personas distintas y en momentos distintos, una y sólo una interpretación particular es la correcta.

Pudiera ser que los participantes en prácticas comunicativas, efectivamente, presupongan de manera ingenua que su propia interpretación es la única correcta. Sin embargo, tan pronto como se vean confrontados con interpretaciones alternativas de la misma materia en cuestión (como es inevitable en sociedades multiculturales), para iniciar un discurso, no tendrán más remedio que adoptar una actitud hipotética accrca de su propia interpretación. Pero esto, a su vez, requerirá de ellos que sean capaces de distinguir, intuitivamente, entre las interpretaciones en conflicto y aquello de lo cual son interpretaciones (sea esto lo que sea en los diferentes casos). Es decir, tendrán que ser capaces de identificar, a través de estas interpretaciones diferentes, los mismos intereses que ellos mismos están intentando articular con la ayuda de sus propias interpretaciones ${ }^{32}$.

Parece claro que la premisa de «una única respuesta correcta» tiene sentido sólo bajo la prcsuposición de una esfera de intereses universalizables, compartidos por todos los seres humanos. Esta presuposición es lo que hace operativo el principio de bivalencia implícito en nuestro uso de la oposición absoluta justo/injusto. Pero en lo que respecta a las diferentes interpretaciones (éticas) -a la luz de las cuales los participantes en un discurso moral entienden el sentido, el valor y la motivación de los intereses salvaguardados por la norma en cuestión-, cn la medida en que puedan ser consideradas interpretaciones de los mismos intereses universalizables, no tienen por qué ser supeditadas a la premisa de «una única interpretación correcta». Este tipo de absolutismo no es realmente ni requerido ni deseable para la defensa consistente de una posición cognitivista sobre cuestiones morales.

" Cuando los participantes no son capaces de identificar los mismos intereses bajo interpretaciones distintas (como en el monento actual parece ser el caso en la discusión sobre el aborto, por ejemplo), sólo parece quedarles la opción de concluir (al menos transitoriamente) que - por csta razón precisamente-puede que no se trate de una cuestión moral en absoluto. 